Article

\title{
Functional Characterization of An Allene Oxide Synthase Involved in Biosynthesis of Jasmonic Acid and Its Influence on Metabolite Profiles and Ethylene Formation in Tea (Camellia sinensis) Flowers
}

\author{
Qiyuan Peng ${ }^{1,2,+}$, Ying Zhou ${ }^{1,+}$, Yinyin Liao ${ }^{1,2}$, Lanting Zeng ${ }^{1,2}$, Xinlan $\mathrm{Xu}^{1}{ }^{1}$, Yongxia Jia ${ }^{1}$, \\ Fang Dong ${ }^{3}$, Jianlong $\mathrm{Li}^{4}{ }^{4}$, Jinchi Tang ${ }^{4}$ and Ziyin Yang ${ }^{1,2, * \mathbb{C}}$ \\ 1 Guangdong Provincial Key Laboratory of Applied Botany \& Key Laboratory of South China Agricultural \\ Plant Molecular Analysis and Genetic Improvement, South China Botanical Garden, Chinese Academy of \\ Sciences, Xingke Road 723, Tianhe District, Guangzhou 510650, China; pqyuan@scbg.ac.cn (Q.P.); \\ yzhou@scbg.ac.cn (Y.Z.); honey_yyliao@scbg.ac.cn (Y.L.); zenglanting@scbg.ac.cn (L.Z.); \\ xxl@scib.ac.cn (X.X.); jyx@scbg.ac.cn (Y.J.) \\ 2 University of Chinese Academy of Sciences, No. 19A Yuquan Road, Beijing 100049, China \\ 3 Guangdong Food and Drug Vocational College, Longdongbei Road 321, Tianhe District, Guangzhou 510520, \\ China; dongfangxyz@163.com \\ 4 Tea Research Institute, Guangdong Academy of Agricultural Sciences \& Guangdong Provincial Key \\ Laboratory of Tea Plant Resources Innovation and Utilization, Dafeng Road 6, Tianhe District, \\ Guangzhou 510640, China; skylong.41@163.com (J.L.); tangjinchi@126.com (J.T.) \\ * Correspondence: zyyang@scbg.ac.cn; Tel./Fax: +86-20-3807-2989 \\ + These authors contributed equally to this work.
}

Received: 19 July 2018; Accepted: 16 August 2018; Published: 18 August 2018

\begin{abstract}
Jasmonic acid (JA) is reportedly involved in the interaction between insects and the vegetative parts of horticultural crops; less attention has, however, been paid to its involvement in the interaction between insects and the floral parts of horticultural crops. Previously, we investigated the allene oxide synthase 2 (AOS2) gene that was found to be the only JA synthesis gene upregulated in tea (Camellia sinensis) flowers exposed to insect (Thrips hawaiiensis (Morgan)) attacks. In our present study, transient expression analysis in Nicotiana benthamiana plants confirmed that CsAOS2 functioned in JA synthesis and was located in the chloroplast membrane. In contrast to tea leaves, the metabolite profiles of tea flowers were not significantly affected by $10 \mathrm{~h} \mathrm{JA}(2.5 \mathrm{mM})$ treatment as determined using ultra-performance liquid chromatography/quadrupole time-of-flight mass spectrometry, and gas chromatography-mass spectrometry. Moreover, JA treatment did not significantly influence ethylene formation in tea flowers. These results suggest that JA in tea flowers may have different functions from JA in tea leaves and other flowers.
\end{abstract}

Keywords: aroma; Camellia sinensis; insect; jasmonic acid; metabolite; tea; volatile

\section{Introduction}

During their evolution, plants are generally exposed to many environmental stresses. Interactions between plants and insects have been intensively studied for many years. In response to insect attack, plants synthesize specialized metabolites or alter their metabolite profiles to provide defensive functions against stresses or assist plant development and reproductive processes [1,2]. Phytohormones are key links between insect attack and the formation of the specialized metabolites. Jasmonic acid (JA) is mostly reported as being involved in interactions between insects and plant vegetative parts [3], while ethylene is mainly known to be responsible for interactions between insects and 
plant floral parts [4]. Herbivore attacks on plant vegetative parts generally increase JA synthesis, leading to upregulated expression of genes involved in the biosynthesis of specialized metabolites with antiherbivore function [5]. Pollination of plant floral parts could lead to an increase in ethylene synthesis that downregulates expression of volatile-related genes and thus reduces the emission of floral volatiles [4]. Such quantitative postpollination changes in floral bouquets help direct pollinators to unpollinated flowers and thus enhances the overall reproductive success [6]. Besides ethylene, it remains to be determined if other phytohormones such as JA play an important role in interactions between insects and plant floral parts. Additionally, most studies have focused on model plants so less attention has been paid to horticultural crops.

Tea (Camellia sinensis) plants are famous horticultural and representative plants in China. The leaves are the most intensively studied part because they have long been used to make tea. In recent years, the flowers of tea plants have attracted increasing interest because they contain functional molecules similar to those found in tea leaves but at higher levels [7]. Some representative metabolites in tea leaves, including catechins, flavonols, caffeine, and amino acids (for example, theanine) are also found in tea flowers [8-10]. Tea flowers also contain greater amounts of some metabolites that occur in tea leaves in lower or trace amounts such as floratheasaponins, spermidine derivatives, acetophenone, and 1-phenylethanol [11-17]. As a potentially rich resource, the chemical profiles and bioactivities of tea flowers have been intensively studied [7]. Tea flowers are generally available from September to December (autumn and winter seasons). Tea leaves are available during the whole year, but tender tea leaves are harvested for making tea products in spring, summer, and autumn seasons, respectively. During the growth of tea leaves, many pest insects attack tea leaves and affect the yield and quality of tea leaves. In response to insect attacks, tea plants emit numerous volatile compounds [18]. Some insect-induced volatiles may play important roles in defense [19,20]. Similar to other plants, formation of these insect-induced volatiles in tea leaves were related to JA induced by insect attacks $[18,21]$. Understanding formation of defensive metabolites in tea leaves exposed to insect attacks will contribute to the future development of the biological control of pest insects in tea plants. Plant defense against insects is generally a systematic defense. Therefore, besides local defense such as investigations from tea leaves, systematic defense, for example investigations from other tissues such as tea flowers, is required, although it remains to be determined if insects attacking tea flowers also affect quality and yield of tea leaves. In our previous study, we found that insect attack (Thrips hawaiiensis (Morgan)) can change the stereochemical configuration of 1-phenylethanol emitted from tea flowers in a manner that was not related to ethylene but may be associated with JA [16]. This allows us to use tea flowers as a model for studying the involvement of JA in interactions between insects and flowers. In the present study, allene oxide synthase 2 (AOS2), which was found to be the only JA synthesis gene upregulated in tea flowers exposed to Thrips hawaiiensis (Morgan) attacks [16], was functionally characterized. Furthermore, the effect of JA on metabolite profiles and ethylene formation in tea flowers were also investigated. The information will advance our understanding of the involvement of phytohormones in interactions between flowers of horticultural crops and insects.

\section{Results}

\subsection{Insect Attack-Upregulated CsAOS2 Functions in JA Synthesis in Tea Flowers}

\subsubsection{Phylogenetic Analysis of CsAOSs and Their Subcellular Localization}

In our previous study, we investigated the effects of $T$. hawaiiensis treatments on the expression levels of JA synthesis-related genes in tea flowers. Only CsAOS2 expression was upregulated by T. hawaiiensis treatment, while other JA synthesis genes were not significantly affected [16]. To further validate the function of CsAOS2 in JA synthesis in tea flowers, in the present study, we first compared the homologous protein sequences of AOSs among different plant species, including GmAOS1 (Glycine max), GmAOS2, HvAOS1 (Hordeum vulgare), HvAOS2, SIAOS1 (Solanum lycopersicum), SIAOS2, SIAOS3, StAOS1 (Solanum tuberosum), StAOS2, StAOS3, NaAOS (Nicotiana attenuata), 
CsAOS1 (C. sinensis), CsAOS2, LuAOS (Linum usitatissimum), AtAOS (Arabidopsis thaliana), OsAOS (Oryza sativa), and ZmAOS1 (Zea mays) [22-25] (Figure 1). The phylogenetic analysis indicated that CsAOS1 had lower similarity with CsAOS2, which only showed $55.01 \%$ (Figure 1).

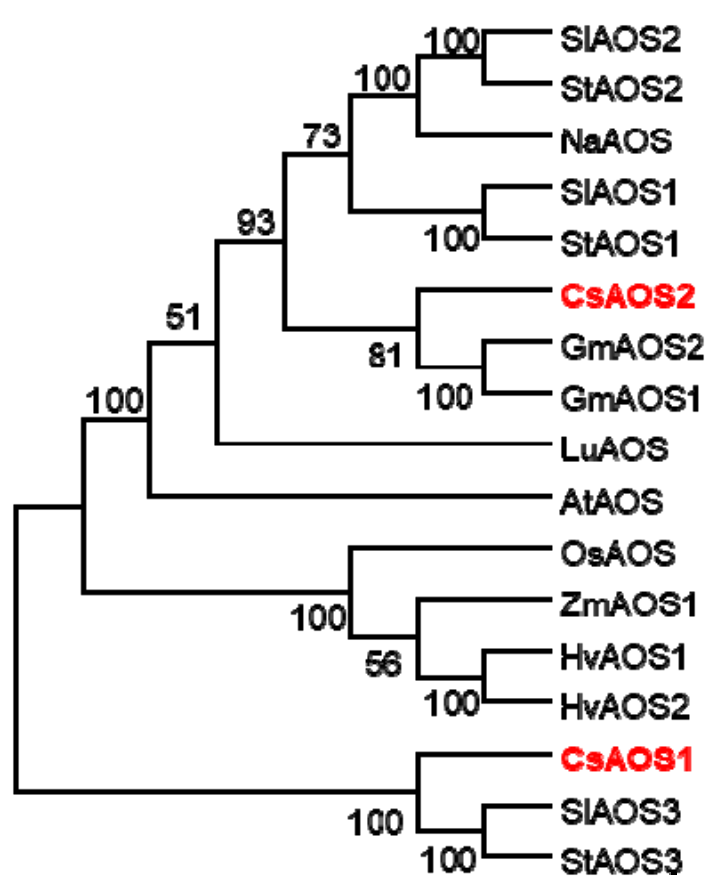

Figure 1. Phylogenetic analyses of plant allene oxidase synthases (AOSs) related to the function of jasmonic acid (JA) synthesis. Phylogenetic tree was performed by software MEGA 5.1 with neighbour joining computation. Sl: Solanum lycopersicum; St: Solanum tuberosum; Na: Nicotiana attenuata; Cs: Camellia sinensis; Gm: glycine max; Lu: Linum usitatissimum; At: Arabidopsis thaliana; Os: Oryza sativa; Zm: zea mays; Hv: Hordeum vulgare. The protein sequences of AOS were SlAOS2 (NP_001274707.1), StAOS2 (CAD29736.2), NaAOS (CAC82911.1), SlAOS1 (CAB88032.1), StAOS1 (CAD29735.1), CsAOS2 (AHY03308.1), GmAOS2 (NP_001236445.1), GmAOS1 (NP_001236432.1), LuAOS (P48417.1), AtAOS (CAA63266.1), OsAOS (AAL17675.1), ZmAOS1 (NP_001105244.2), HvAOS1 (CAB86383.1), HvAOS2 (CAB86384.1), CsAOS1 (BAU24784.1), SlAOS3 (NP_001265949.1), and StAOS3 (CAI30876.1).

It was reported that wounding causes the release of linoleic acid (LA) from chloroplast lipids, catalyzed by lipoxygenases (LOX), AOS, and allene oxide cyclase (AOC) to 12-oxo-phytodienoic acid. 12-oxo-Phytodienoic acid produced in the chloroplast is transported to the peroxisome where it is used to synthesize JA [26-29]. In the present study, we investigated the subcellular localization of CsAOS1 and CsAOS2 by GFP-fusion protein pCAMBIA3300. CsAOS1 was located in the plasma membrane and CsAOS2 was detected in the chloroplast membrane (Figure 2).

2.1.2. Transient Expression Analysis in N. benthamiana Plants Confirmed That CsAOS2 Functioned in JA Synthesis

To further confirm whether CsAOS2 functions in JA synthesis, transient expression analysis in $N$. benthamiana plants was employed (Figure 3). As the JA synthetic pathway derived from LA involves several enzymes/genes, the overexpression of individual genes may be insufficient to increase JA content. Therefore, mechanical damage was used to activate the genes in the JA synthetic pathway. In the present study, there were two groups of $N$. benthamiana plants including control (vector) and CsAOS2 overexpression plants. These two groups of plants were treated by mechanical damage. As shown in Figure 3A, JA content in the control increased at $1 \mathrm{~h}$ after mechanical damage (damage by making 12 holes on one leaf using needle) because of upregulation of the genes in the JA synthetic pathway. Furthermore, the CsAOS2 overexpression group had higher JA content than the control 
group at $1 \mathrm{~h}$ after the mechanical damage, indicating that CsAOS2 functions in JA synthesis. At $12 \mathrm{~h}$ after mechanical damage, JA content in both groups decreased; this was reasonable given that the JA response is relatively quick when plants are exposed to stresses [30,31]. We also investigated the effect of mechanical damage treatments of different intensities on functional characterization of CsAOS2 at $1 \mathrm{~h}$ after mechanical damage. Figure 3B shows the two mechanical damage methods. The first method involved prodding 12 holes in each leaf using a needle. The second method involved cutting the leaves into eight parts. Different treatments led to different levels of JA increase in the CsAOS2 overexpression group. This is because the intensity of the mechanical damage can affect the degree of expression changes observed for several genes in the JA synthetic pathway; these variation ranges may be higher than the overexpression level of CsAOS2.
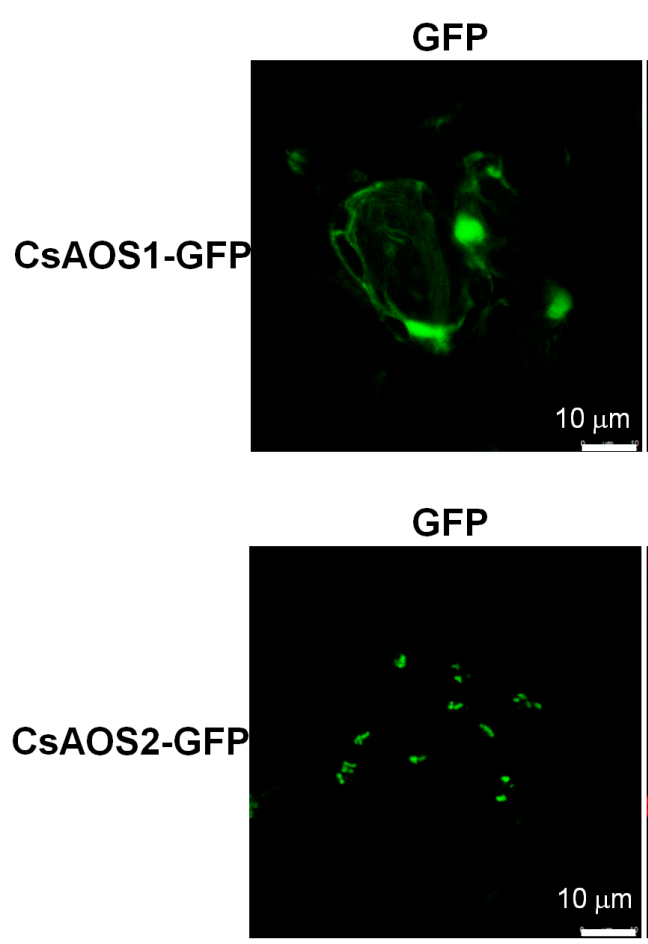

\section{Chloroplast}

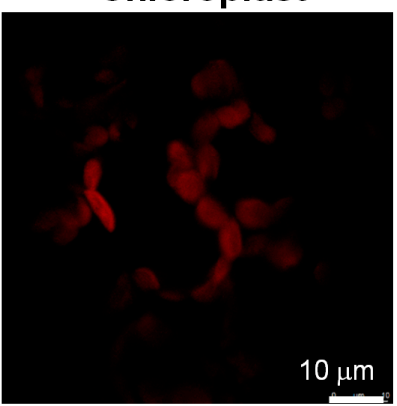

Chloroplast

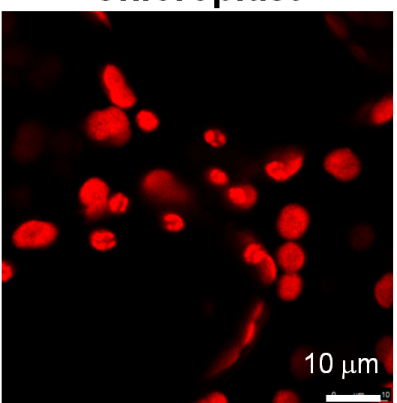

Merge

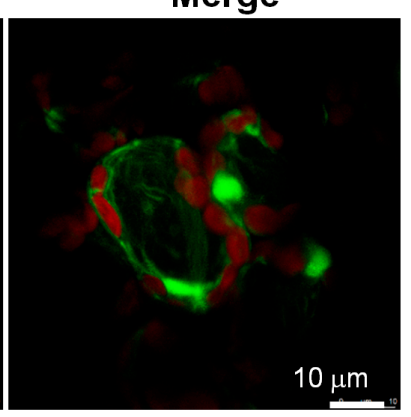

Merge

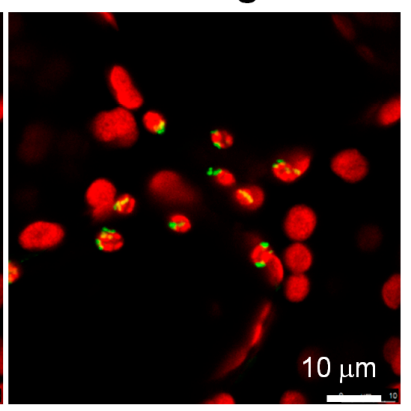

Figure 2. Subcellular localizations of CsAOS1 and CsAOS2. The CsAOS1-GFP and CsAOS2-GFP fusion proteins were transiently expressed in Nicotiana benthamiana. Green fluorescence indicated CsAOS1-GFP and CsAOS2-GFP fusion protein. Red fluorescence showed the chloroplast auto-fluorescence.
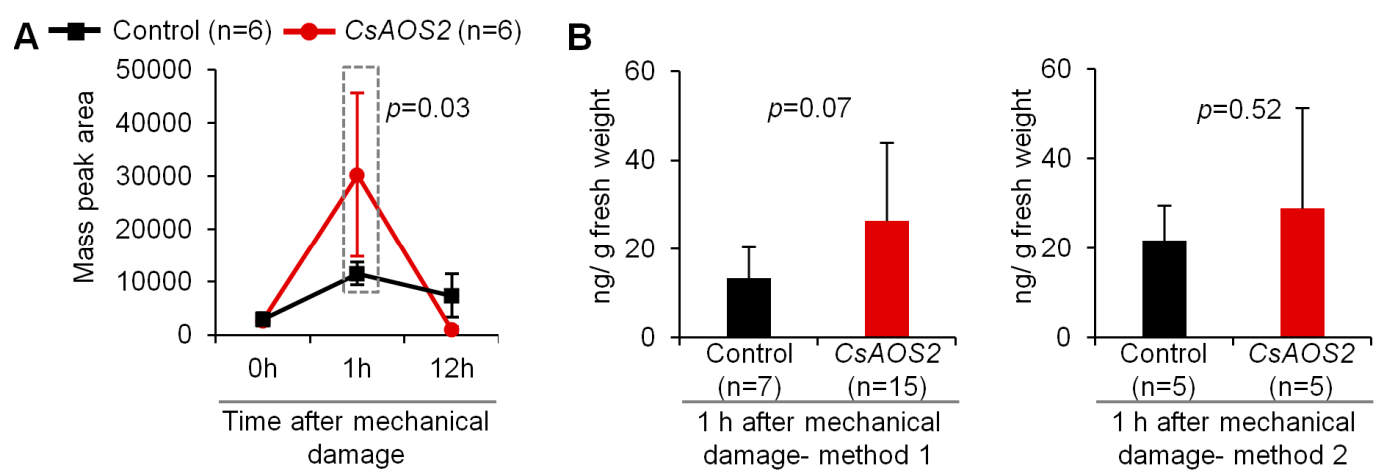

Figure 3. Comparison of JA contents in control and overexpression of CsAOS2 in N. benthamiana. (A) The treated leaves were harvested at the indicate time points $0 \mathrm{~h}, 1 \mathrm{~h}$, and $12 \mathrm{~h}(n=6)$, after mechanical damage; (B) Mechanical damage method 1 was damage by making 12 holes on one leaf using needle. Mechanical damage method 2 was damage by cutting one leaf into eight pieces. The treated leaves were harvested at $1 \mathrm{~h}$, after mechanical damage. Data represent the mean value \pm standard deviation. 
2.2. In Contrast to Tea Leaves, the Metabolite Profiles of Tea Flowers Were Not Significantly Affected by JA Treatment

It is well-known that JA can affect metabolite profiles in plants, especially vegetative parts, for example, the secondary metabolites in Nicotiana attenuata leaves [32]. To investigate whether JA affect the metabolite profiles in tea flowers, tea flowers were treated with JA ( $2.5 \mathrm{mM})$ for $10 \mathrm{~h}$ (from flower half-open stage to fully-open stage) and metabolite profiles were subsequently analyzed by gas chromatography-mass spectrometry (GC-MS, for volatile metabolites) and ultra-performance liquid chromatography/quadrupole time-of-flight mass spectrometry (UPLC-QTOF-MS, for nonvolatile metabolites). Emitted volatile and internal volatile profiles were not significantly changed in JA-treated tea flowers (Figure 4A). In the present study, UPLC-QTOF-MS was equipped with either an ACQUITY UPLC BEH Amide column (suitable for determination of high polarity metabolites) or an ACQUITY UPLC HSS T3 C18 column (suitable for determination of low polarity metabolites). In analyses with separations using both columns and positive or negative MS modes, nonvolatile metabolite profiles were also not significantly changed in JA-treated tea flowers (Figure 4B). In contrast, we also investigated the effects of the same JA treatment on metabolite profiles in tea leaves. Unlike tea flowers, volatile metabolite profiles and partial nonvolatile metabolite profiles of tea leaves were changed (Figure 5). These results suggest that the responses of metabolites to JA in tea flowers was weaker than in tea leaves.

A

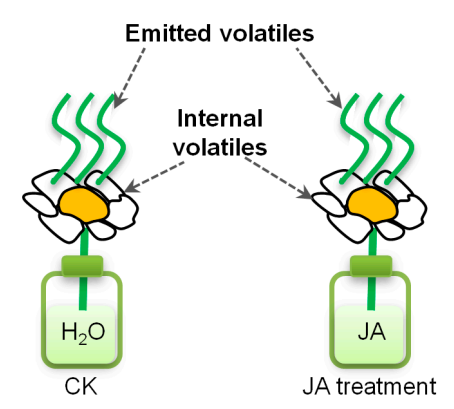

B

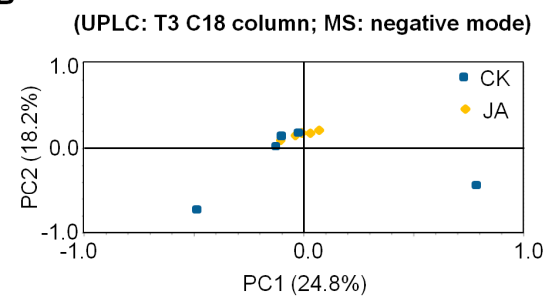

(UPLC: Amide column; MS: negative mode)

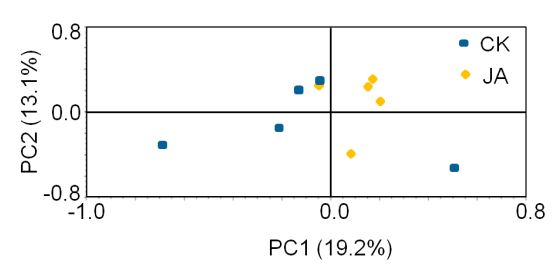

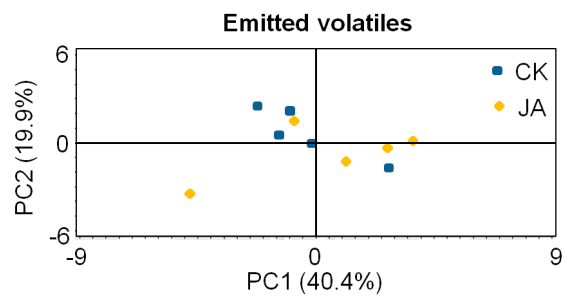

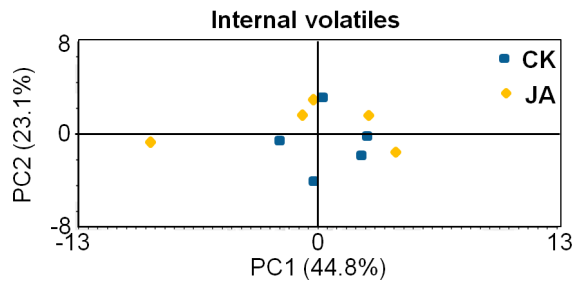

(UPLC: T3 C18 column; MS: positive mode)

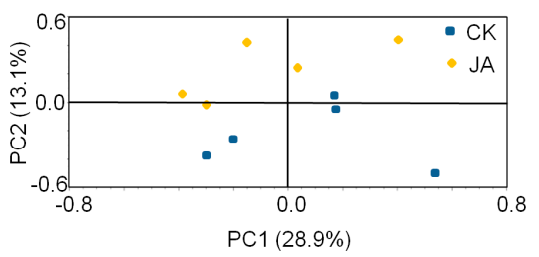

(UPLC: Amide column; MS: positive mode)

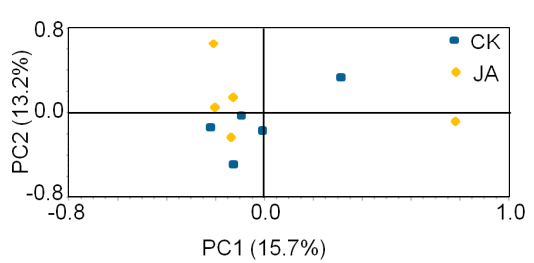

Figure 4. Effect of JA treatment on metabolite profiles of tea flowers. (A) JA treatment: $2.5 \mathrm{mM}$ JA dissolved in $0.5 \%$ ethanol; control: distilled water dissolved in $0.5 \%$ ethanol. Principal component analysis (PCA) of emitted volatiles and internal volatiles, which were analyzed by GC-MS $(n=5)$.

(B) PCA analysis of nonvolatile metabolites, which were analyzed by UPLC-QTOF-MS $(n=5)$. 
A

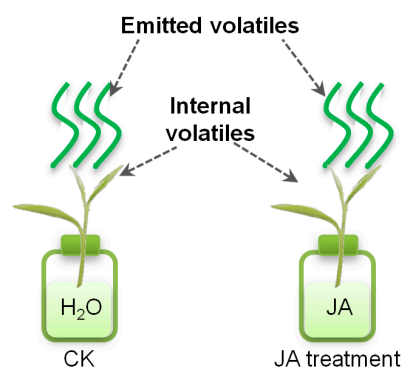

B
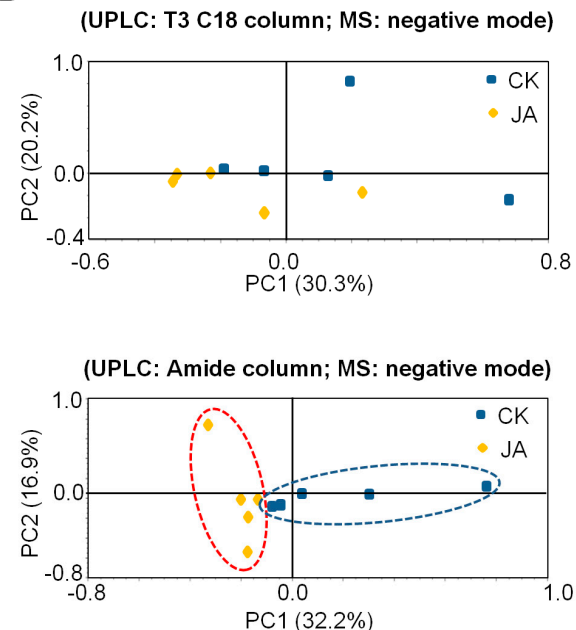

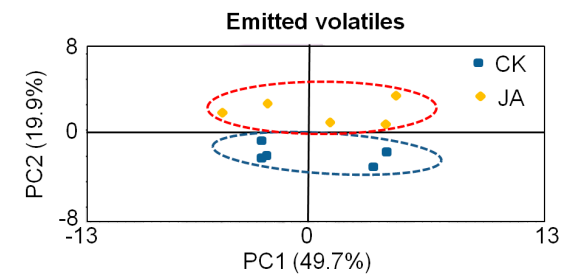

Internal volatiles

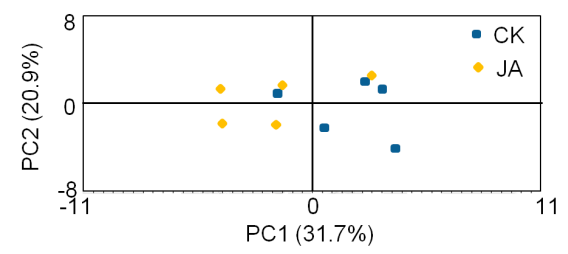

(UPLC: T3 C18 column; MS: positive mode)

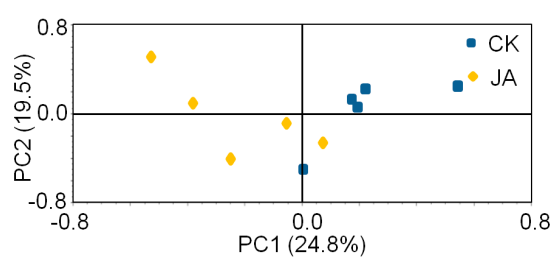

(UPLC: Amide column; MS: positive mode)

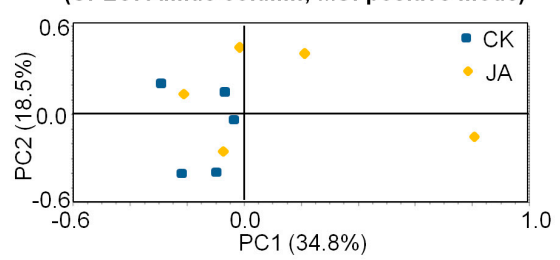

Figure 5. Effect of JA treatment on metabolite profiles of tea leaves. (A) JA treatment: $2.5 \mathrm{mM} \mathrm{JA}$ dissolved in $0.5 \%$ ethanol; control: distilled water dissolved in $0.5 \%$ ethanol. Principal component analysis (PCA) of emitted volatiles and internal volatiles, which were analyzed by GC-MS $(n=5)$. (B) PCA analysis of nonvolatile metabolites, which were analyzed by UPLC-QTOF-MS $(n=5)$.

\subsection{JA Treatment Did Not Influence Ethylene Formation in Tea Flowers}

It has been reported that JA can enhance ethylene formation in dendrobium and petunia flowers [33]. Therefore, we also investigated whether JA in tea flowers has a similar effect on ethylene formation. S-Adenosyl-L-methionine synthetase (SAM) converts methionine into S-adenosyl-L-methionine (S-AdoMet), the precursor of ethylene. This is followed by ethylene biosynthesis. In the first step, $S$-AdoMet is converted into 1-aminocyclopropane-1-carboxylic acid (ACC) by ACC synthase (ACS). ACC oxidase (ACO) then oxidizes ACC to ethylene [34]. The key genes involved in ethylene formation, including a structural gene ACS and an ethylene receptor ethylene-insensitive (EIN) gene, found in C. sinensis were analyzed. In flowers of $C$. sinensis cv. Jinxuan (middle and small leaf species), the expression levels of these ethylene synthesis-related genes were not significantly affected by JA treatment (Figure 6A). To further confirm the relationship between ethylene and JA we measured the ethylene levels released from flowers (a big leaf species cv. Yinghong NO. 9) after JA treatment to exclude the effects of different tea cultivars (Figure 6B). Like ethylene synthesis-related gene expression levels, ethylene content was not significantly affected by JA treatment (Figure 6B). These results suggest that JA in tea flowers may have different functions than in the flowers of dendrobium and petunia [33]. 
A
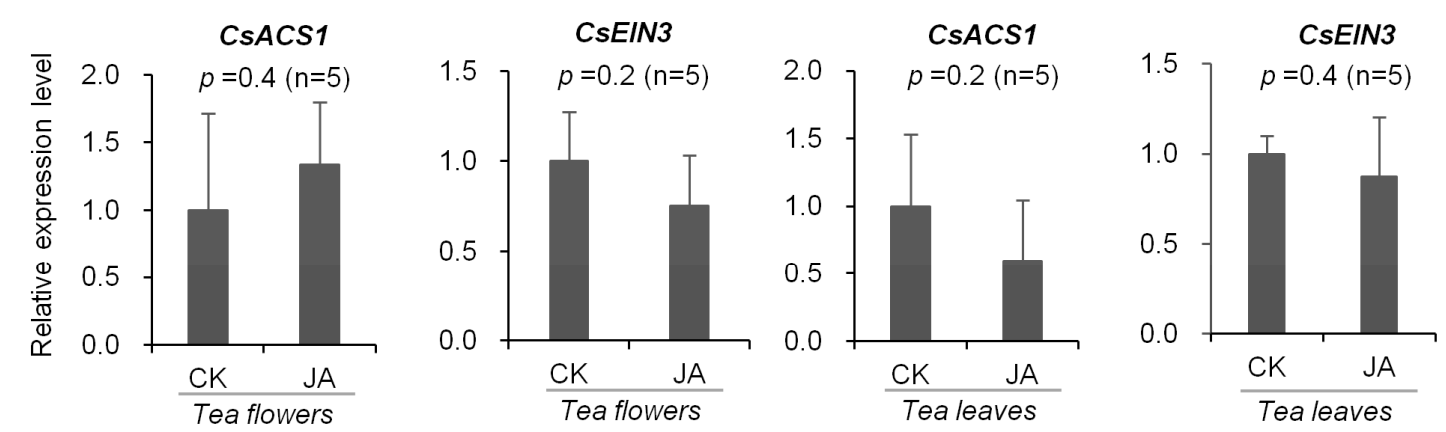

B
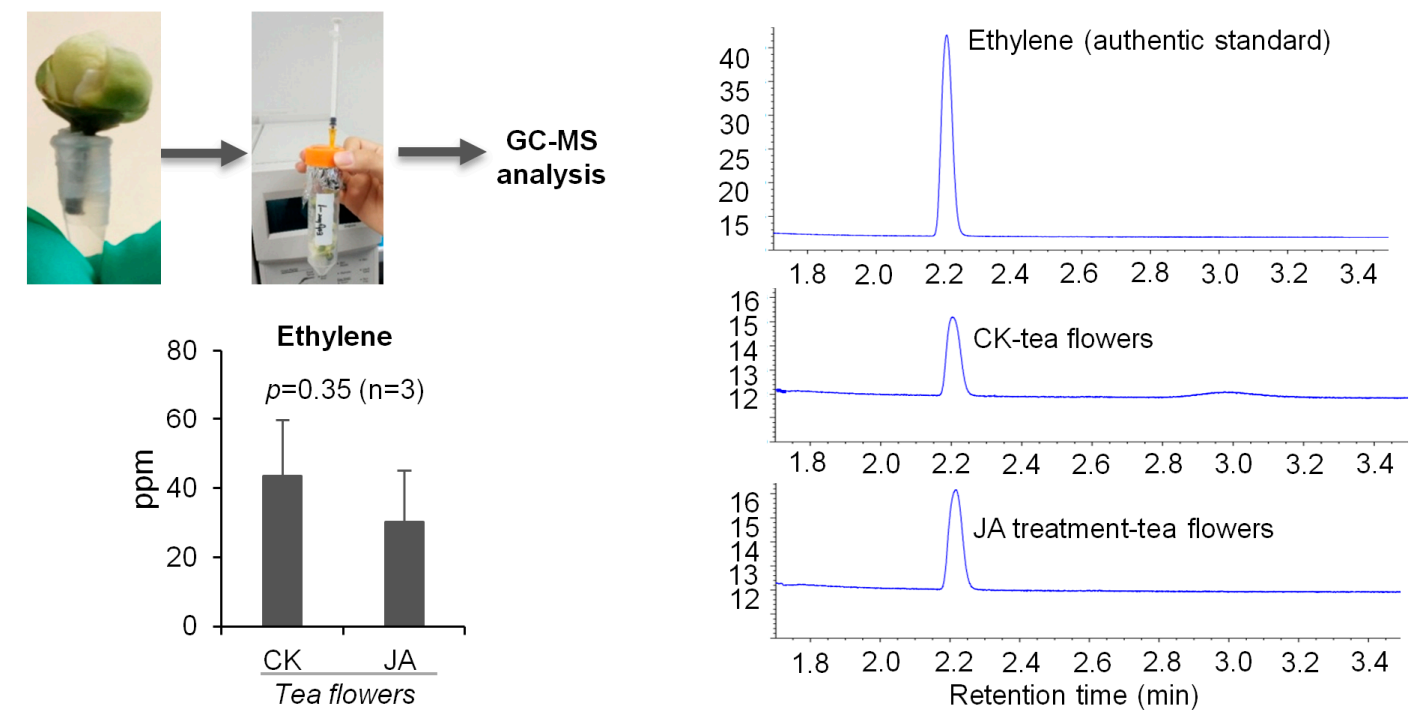

Figure 6. Effect of JA treatment on ethylene expression level and emission in tea flowers. CK, tea flowers without JA treatment. (A) Expression levels of ethylene synthesis genes and transcription factor in tea flowers and leaves, respectively which were treated by JA. Tea flowers and leaves were $C$. sinensis cv. Jinxuan. (B) The content of flowers ethylene were collected and analysis was conducted by GC. Tea flowers were C. sinensis cv. Yinghong NO. 9.

\section{Discussion}

JA is widely present in the plant kingdom and belongs to the family of oxygenated fatty acid derivatives. It is synthesized via the oxidative metabolism of polyunsaturated fatty acids [35]. LA is oxygenated to 13(S)-hydroxy linolenic acid (13-HPOT) by the action of LOX. Under the actions of AOS and AOC, 13-HPOT then can be converted to 12-oxophytodienoic acid that can then be transformed to JA through reduction and three steps of $\beta$-oxidation. Among the enzymes in the JA synthesis pathway, LOXs are the most intensively studied enzymes. Plant LOXs are divided into two types including 9-LOXs and 13-LOXs. In the model plant $N$. attenuata, three different LOX isoforms are known. NaLOX3 is confirmed to be involved in the JA pathway and NaLOX2 has been shown to the pathway for green leaf volatiles [36,37]. In response to herbivore attack, upregulation of LOX3 in N. attenuata leaf is more sensitive than other genes involved in the JA pathway [5]. There are many reports concerning the effect of herbivore attack on genes in the JA synthesis pathway in plant vegetative parts, while little corresponding information is available for plant floral parts. Tea plants have no successful genetic transformation system, making it difficult to obtain in vivo evidence of metabolic pathways in tea plants. Our current knowledge concerning phytohormone and metabolite biosynthesis in tea plants is mostly based on reported findings for other plant species. Although some of these pathways are shared among plant species, there may also be variation among species because of the complexity of 
the biosynthetic networks. Therefore, direct investigations of JA synthesis in tea plants are required. In the present study, CsAOS2 was confirmed to be involved in the biosynthesis of JA in tea flowers (Figure 3). The AOSs have been isolated and functionally characterized in several species of plants such as Lycopersicon esculentum, Hordeum vulgare, and Solanum tuberosum. These AOSs were reported to be located in the chloroplasts [26-28,38]. These results suggest that CsAOS2, rather than CsAOS1, may be involved in JA biosynthesis in tea flowers. In future work, it would be of interest to investigate why CsAOS2 was upregulated in tea flowers exposed to T. hawaiiensis treatment while other genes were not significantly affected.

There are a number of studies on the involvement of phytohormones in interactions between insects and flowers or leaves. Although some cases may be different in different plants, it is relatively universal that in most plants JA is typically reported to be involved in interactions between insects and plant vegetative parts while ethylene is mostly reported to be involved in interactions between insects and plant floral parts. Salicylic acid is mainly reported to be involved in interactions between microorganisms and plants, but it is also related to the interaction between insects and plant vegetative parts in some cases. More evidence suggests that, rather than individual phytohormones, interactions between insects and plants involve several phytohormones working together. Moreover, the phytohormone pathways may have antagonistic/synergistic cross-talk. For example, in maize, fungal infection reduced the emission of volatiles induced by lepidopteran herbivory alone by about $50 \%$, possibly suggesting a diversion of plant resources from antiherbivore to presumptive antipathogen defenses. The authors hypothesized that fungal infection could stimulate the SA-based signal transduction pathway that would reduce signaling through the herbivore-triggered JA pathway because of negative cross-talk [39]. In contrast to plant vegetative parts, phytohormone cross-talk in plant floral parts is less studied. There are a few reports that JA can affect ethylene formation in flowers of dendrobium and petunia [33]. However, in the present study, JA did not significantly affect ethylene formation in tea flowers (Figure 6), suggesting that JA may play different roles in different plant flowers. Additionally, in contrast to tea leaves, the metabolite profiles of tea flowers were not significantly affected by JA treatment (Figures 4 and 5). This also suggests that JA may have different effects in different tissues of the same plant. In tea leaves, JA treatment mainly increased emission of volatiles compounds such as $\alpha$-farnesene, $\beta$-ocimene, (Z)-3-hexen-1-ol, linalool, benzyl alcohol, benzyl nitrile, indole, etc. $[18,21]$. Some volatiles emitted from tea leaves can attract natural enemies of the pest insects $[19,20]$. In our previous study, JA can change the stereochemical configuration of 1-phenylethanol emitted from tea flowers [16]. It will be of interest to investigate whether JA is also associated with the alteration of certain metabolites in tea flowers. Recently, Li et al. uncovered the defensive function of JA signaling in N. attenuata flowers that includes components that tailor JA signaling to provide flower-specific defenses [40]. Further studies on the relationship between insect-induced JA increase in tea flowers and their defense against insect attacks will help us further understand the roles of flowers in tea plants and systematic defense of tea plants.

\section{Materials and Methods}

\subsection{Plant Materials and Treatments}

The flowers and leaves of $C$. sinensis cv. 'Jinxuan' and flowers of cv. 'Yinghong No. 9' were sampled from the Tea Research Institute, Guangdong Academy of Agricultural Sciences $\left(23^{\circ} \mathrm{N}, 113^{\circ} \mathrm{E}\right.$, Yingde, China).

For phytohormone treatments, half-open flowers and a bud with two leaves were placed in solution A and solution B, respectively. Solution A contained $2.5 \mathrm{mM} \mathrm{JA}$ dissolved in $0.5 \%$ ethanol $(v / v)$, solution B contained distilled water with $0.5 \%$ ethanol $(v / v)$. All treatments were performed for $10 \mathrm{~h}$ at room temperature. Groups of three treated flowers and groups of five treated leaves were used as one replicate, respectively, for collecting volatile emissions. Groups of five flowers or leaves were 
collected as one replicate for internal volatiles, nonvolatile metabolites, and phytohormone analyses, respectively. Each treatment was performed in quintuplicate.

\subsection{Extraction and Analysis of Volatile Metabolites}

For extraction of internal volatile metabolites, the treated flowers were ground with liquid nitrogen before $0.5 \mathrm{~g}$ of finely powdered flowers was extracted in $5 \mathrm{~mL} \mathrm{CH}_{2} \mathrm{Cl}_{2} ; 50 \mu \mathrm{L} 0.1 \mathrm{mM}$ ethyl $n$-decanoate was used as an internal standard. Extractions were shaken for $4 \mathrm{~h}$ at room temperature. The process was the same as previously described [16]. The extraction was then dried over anhydrous sodium sulfate and concentrated to $200 \mu \mathrm{L}$ using nitrogen gas before $1 \mu \mathrm{L}$ of the concentrate was subjected to analysis by GC-MS.

For the collection of emitted volatile metabolites, three flowers, or five tea shoots (one bud and two leaves per shoot), were placed into 1-L beakers and then sealed with silver paper. The emitted volatiles were collected as previously described [16]. The headspace volatiles were absorbed by solid phase microextraction (SPME, 50/30 $\mu \mathrm{m}$, DVB/CAR/PDMS, Stableflex $(2 \mathrm{~cm})$ ) (Supelco Inc., Bellefonte, Pennsylvania, USA) for $10 \mathrm{~min}$ (for tea flowers) and $30 \mathrm{~min}$ (for tea leaves), respectively, at room temperature and then analyzed by GC-MS.

The GC-MS was equipped with a SUPELCOWAXTM 10 column (Supelco Inc., $30 \mathrm{~m} \times 0.25 \mathrm{~mm} \times$ $0.25 \mu \mathrm{m}$ ). The injector temperature was $230^{\circ} \mathrm{C}$, the split ratio was 5:1 (for flower internal volatiles), split 10:1 (for flower-emitted volatiles), and splitless (for tea leaf-emitted and internal volatiles); the helium (carrier gas) flow rate was $1.0 \mathrm{~mL} / \mathrm{min}$. The initial temperature of the column was $60^{\circ} \mathrm{C}$, maintained for $3 \mathrm{~min}$, followed by a ramped temperature rise to $240{ }^{\circ} \mathrm{C}$ at a rate of $4{ }^{\circ} \mathrm{C} / \mathrm{min}$ before being held at $240^{\circ} \mathrm{C}$ for $20 \mathrm{~min}$. Full scan mode (mass range $m / z 40-200$ ) was operated for MS analysis.

\subsection{Extraction and Analysis of Nonvolatile Metabolites}

One hundred mg of finely powdered flowers was extracted with $3 \mathrm{~mL}$ cold $70 \%$ methanol using ultrasonic extraction for $30 \mathrm{~min}$ under ice-cold conditions. The extractions were centrifuged for $10 \mathrm{~min}$ at $10,000 \times \mathrm{g}$ at $4{ }^{\circ} \mathrm{C}$ to obtain the supernatant and then filtered through a $0.22 \mu \mathrm{m}$ membrane. Samples were analyzed by UPLC-QTOF-MS (Waters Corporation, Milford, Massachusetts, MA, USA). Each sample $(5 \mu \mathrm{L})$ was injected into a Waters ACQUITY UPLC HSS T3 C18 column $(2.1 \mathrm{~mm} \times 100 \mathrm{~mm}$, $1.8 \mu \mathrm{m})$. Solvent A was Milli-Q water with $0.1 \%(v / v)$ formic acid. Solvent B was acetonitrile with $0.1 \%(v / v)$ formic acid. The solvent gradient was as follows: solvent B was started at $10 \%$ then linearly increased to $30 \%$ within $25 \mathrm{~min}$, then increased to $95 \%$ within $15 \mathrm{~min}$ and kept for $4 \mathrm{~min}$ before being dropped to $10 \%$ in $0.1 \mathrm{~min}$ and maintained for $4 \mathrm{~min}$. The flow rate was $0.3 \mathrm{~mL} / \mathrm{min}$ and the column temperature was $30^{\circ} \mathrm{C}$. The electrospray ionization operated on positive and negative modes, respectively. The MS conditions of the positive mode were as follows: capillary voltage was $3 \mathrm{kV}$, source temperature was $100{ }^{\circ} \mathrm{C}$, desolvation temperature was $350^{\circ} \mathrm{C}$, cone gas flow was $50 \mathrm{~L} / \mathrm{h}$, and desolvation gas flow was $650 \mathrm{~L} / \mathrm{h}$. The MS conditions of the negative mode were as follow: capillary voltage was $1.5 \mathrm{kV}$, source temperature was $100{ }^{\circ} \mathrm{C}$, desolvation temperature was $300{ }^{\circ} \mathrm{C}$, cone gas flow was $50 \mathrm{~L} / \mathrm{h}$, and desolvation gas flow was $600 \mathrm{~L} / \mathrm{h}$.

We also used an ACQUITY UPLC BEH Amide column $(2.1 \mathrm{~mm} \times 100 \mathrm{~mm}, 1.7 \mu \mathrm{m})$ to identify some polar compounds. Solvent A was Milli-Q water with $0.1 \%(v / v)$ formic acid. Solvent B was acetonitrile with $0.1 \%(v / v)$ formic acid. The solvent gradient was as follows: solvent $B$ was started at $90 \%$, then linearly decreased to $50 \%$ within $30 \mathrm{~min}$ and kept for $4 \mathrm{~min}$ before it was increased to $90 \%$ in $0.1 \mathrm{~min}$ and maintained for $4 \mathrm{~min}$. The flow rate was $0.4 \mathrm{~mL} / \mathrm{min}$. The column temperature was $30^{\circ} \mathrm{C}$. The electrospray ionization operated on positive and negative modes, respectively. The MS conditions of the positive mode were as follows: capillary voltage was $2 \mathrm{kV}$, source temperature was $100{ }^{\circ} \mathrm{C}$, desolvation temperature was $350{ }^{\circ} \mathrm{C}$, cone gas flow was $50 \mathrm{~L} / \mathrm{h}$, and desolvation gas flow was $600 \mathrm{~L} / \mathrm{h}$. The MS conditions of the negative mode were as follows: capillary voltage was $0.5 \mathrm{kV}$, source temperature was $100{ }^{\circ} \mathrm{C}$, desolvation temperature was $250{ }^{\circ} \mathrm{C}$, cone gas flow was $50 \mathrm{~L} / \mathrm{h}$, and desolvation gas flow was $400 \mathrm{~L} / \mathrm{h}$. 


\subsection{Gene Cloning}

Homologous genes of $A O S$ were identified using C. sinensis transcriptome information. RNA was then isolated from $150 \mathrm{mg}$ of flowers (cv. Jinxuan) using a Quick RNA Isolation Kit (Huayueyang, Beijing, China) and $20 \mu \mathrm{L}$ of cDNA was synthesized from $500 \mathrm{ng}$ of total RNA using a Prime Script ${ }^{\mathrm{TM}} \mathrm{RT}$ reagent Kit with gDNA Eraser (Takara Biotechnology, Dalian, China) according to the manufacturer's instructions. Reverse transcription was carried out at $37^{\circ} \mathrm{C}$ for $15 \mathrm{~min}$, followed by $85^{\circ} \mathrm{C}$ for $5 \mathrm{~s}$. Genes were obtained by polymerase chain reaction (PCR) using this cDNA as the template. We use nested PCR to successfully obtain the sequences. Two rounds of PCR primers are listed in Tables S1 and S2. The conditions of the first reaction were as follows; $98^{\circ} \mathrm{C}$ for $2 \mathrm{~min}$ followed by 35 cycles of $98^{\circ} \mathrm{C}$ for $10 \mathrm{~s}, 57^{\circ} \mathrm{C}$ for $15 \mathrm{~s}$, and $72{ }^{\circ} \mathrm{C}$ for $1 \mathrm{~min}$ before samples were maintained at $16^{\circ} \mathrm{C}$. The second reaction consisted of $98^{\circ} \mathrm{C}$ for $2 \mathrm{~min}$ followed by two cycles of $98^{\circ} \mathrm{C}$ for $10 \mathrm{~s}, 47^{\circ} \mathrm{C}$ for $15 \mathrm{~s}$, and $72{ }^{\circ} \mathrm{C}$ for $1 \mathrm{~min}$. This was followed by 32 cycles of $98^{\circ} \mathrm{C}$ for $10 \mathrm{~s}, 61^{\circ} \mathrm{C}$ for $15 \mathrm{~s}$, and $72{ }^{\circ} \mathrm{C}$ for $1 \mathrm{~min}$ before the samples were maintained at $16^{\circ} \mathrm{C}$. Products were gel purified, cloned into the pGEM-T easy vector with T4 ligase, and sequenced. The phylogenetic analyses were performed by MEGA 5.1 software using the neighbor-joining method.

\subsection{Subcellular Location Analysis of CsAOSs}

The complete sequence of the CsAOS ORF was cloned and inserted into pCambia3300-GFP vectors using an In-Fusion ${ }^{\circledR}$ HD Cloning Kit (Takara Biotechnology. The construct was transformed into Agrobacterium tumefaciens strain GV3101 by chemical transfection. One single colony of Agrobacterium was then inoculated into $5 \mathrm{~mL}$ LB with appropriate antibiotics (Rif, Gen, and Kana) and grown overnight at $28^{\circ} \mathrm{C}$. Subsequently, $1 \mathrm{~mL}$ of the overnight culture was added to $25 \mathrm{~mL}$ LB plus $20 \mu \mathrm{M}$ acetosyringone and grown again overnight. The bacteria were precipitated at $5000 \times \mathrm{g}$ for $8 \mathrm{~min}$ before the pellet was resuspended in resuspension buffer $(10 \mathrm{mM} \mathrm{MgCl} 2,10 \mathrm{mM} \mathrm{MES-K} \mathrm{(pH} \mathrm{5.6),}$ and $100 \mu \mathrm{M}$ acetosyringone). The final $\mathrm{A} 600$ was be adjusted to $0.4 \mathrm{~nm}$ and samples were left at room temperature for at least $2 \mathrm{~h}$ before being infiltrated into $N$. benthamiana leaves using a needle-less syringe. After 5 days, the fluorescence-labeled protein was observed under a confocal laser-scanning microscope Zeiss LSM 510 (Carl Zeiss, Jena, Germany).

\subsection{Analysis of the Activities of CSAOS2 in N. benthamiana Overexpression Lines}

CsAOS2 was transiently expressed in N. benthamiana as described above. Leaves from these plants were mechanically damaged using a needle before the treated leaves were harvested at the indicated time points $(0 \mathrm{~h}, 1 \mathrm{~h}$, and $12 \mathrm{~h})$ and immediately frozen in liquid nitrogen. Next, two types of mechanical damage were applied to analyze the function of CsAOS $1 \mathrm{~h}$ after treatments. One method involved needle puncture while in the other the leaf was cut into eight pieces. In each instance, samples were then immediately frozen in liquid nitrogen.

Next, $300 \mathrm{mg}$ of finely powdered leaves was extracted with $2 \mathrm{~mL}$ cold ethyl acetate. The extraction was vortexed for $30 \mathrm{~s}$ and then ultrasonically extracted for $20 \mathrm{~min}$ under ice-cold conditions. Subsequently, the solution was centrifuged at $12,000 \times \mathrm{g}$ at $4{ }^{\circ} \mathrm{C}$ for $10 \mathrm{~min}$ to obtain the supernatant. Next, $1 \mathrm{~mL}$ ethyl acetate was added to the residue and the samples were vortexed for $30 \mathrm{~s}$ before being ultrasonically extracted for $10 \mathrm{~min}$ under ice-cold conditions. The supernatants were combined and dried under nitrogen gas. Dried residues were resuspended in $200 \mu \mathrm{L}$ methanol containing $40 \mathrm{ng}$ of $\left[{ }^{2} \mathrm{H}_{5}\right]$-JA $(2,4,4-\mathrm{d} 3$; acetyl-2, 2-d2) as an internal standard and then passed through a $0.22 \mu \mathrm{m}$ filter membrane.

The extraction was analyzed by UPLC-QTOF-MS (Waters Corporation, Milford, USA) running in the $\mathrm{MS}^{2}$ acquisition mode. Each sample $(5 \mu \mathrm{L})$ was injected onto a Waters ACQUITY UPLC HSS T3 C18 column $(2.1 \mathrm{~mm} \times 100 \mathrm{~mm}, 1.8 \mu \mathrm{m})$. Solvent A was Milli-Q water with $0.1 \%(v / v)$ formic acid and solvent B was acetonitrile with $0.1 \%(v / v)$ formic acid. The solvent gradient was as follows: solvent B was started at $20 \%$ then linearly increased to $35 \%$ within $10 \mathrm{~min}$, and then increased to $95 \%$ in $0.1 \mathrm{~min}$ 
and maintained for $3 \mathrm{~min}$ before being dropped to $20 \%$ in $0.1 \mathrm{~min}$ and maintained for $3 \mathrm{~min}$. The flow rate was $0.4 \mathrm{~mL} / \mathrm{min}$ and the column temperature was $30^{\circ} \mathrm{C}$. The electrospray ionization operated on negative mode. The MS conditions were as follows: capillary voltage was $1.5 \mathrm{kV}$, source temperature was $100{ }^{\circ} \mathrm{C}$, desolvation temperature was $300{ }^{\circ} \mathrm{C}$, cone gas flow was $50 \mathrm{~L} / \mathrm{h}$, and desolvation gas flow was $600 \mathrm{~L} / \mathrm{h}$.

\subsection{Transcript Expression Analyses of Genes in Ethylene Formation in Tea Flowers}

RNA was isolated from $150 \mathrm{mg}$ of flowers (cv. Jinxuan) and $100 \mathrm{mg}$ of leaves (cv. Jinxuan) using a Quick RNA Isolation Kit (Huayueyang, Beijing, China). Then, $20 \mu \mathrm{L}$ of cDNA was synthesized from 500 ng of total RNA using Prime Script ${ }^{\mathrm{TM}}$ RT reagent Kit with gDNA Eraser (Takara Biotechnology, Dalian, China) according to the manufacturer's instructions. Reverse transcription was carried out at $37^{\circ} \mathrm{C}$ for $15 \mathrm{~min}$, followed by $85^{\circ} \mathrm{C}$ for $5 \mathrm{~s}$. The primers used in the quantitative real-time PCR (qRT-PCR) are listed in Table S3. Elongation factor-1a (EF-1a) was used as an internal reference.

The qRT-PCR analysis reactions were performed in a total volume of $20 \mu \mathrm{L}$, including $0.8 \mu \mathrm{L}$ of each primer $(10 \mu \mathrm{M}), 2 \mu \mathrm{L}$ cDNA diluted 50-fold, $10 \mu \mathrm{L}_{\text {iTaq }}{ }^{\mathrm{TM}}$ Universal SYBR ${ }^{\circledR}$ Green Supermix

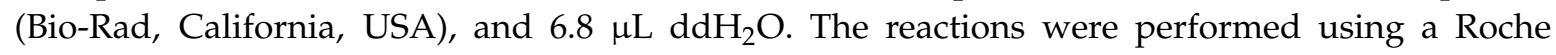
LightCycler 480 (Roche Applied Science, Mannheim, Germany). The PCR program was initiated with a preliminary step of $5 \mathrm{~min}$ at $95^{\circ} \mathrm{C}$, followed by 45 cycles of $95^{\circ} \mathrm{C}$ for $15 \mathrm{~s}$ and $60^{\circ} \mathrm{C}$ for $1 \mathrm{~min}$. A melting curve was generated for each sample at the end of each run to ensure the purity of the amplified products. The $2^{-\Delta \Delta C t}$ method was used to calculate fold change as previously described [16].

\subsection{Collection and Analysis of Ethylene in Tea Flowers}

For the collection of emitted ethylene, each flower was placed in a $200 \mu \mathrm{L}$ centrifuge tube with $2.5 \mathrm{mM}$ JA dissolved in $0.5 \%$ ethanol $(v / v)$; nine of these flowers were then placed in a $50 \mathrm{~mL}$ centrifuge tube that was then sealed with silver paper. Air in the tube was extracted using a 1-mL syringe. These $1-\mathrm{mL}$ gas samples were analyzed with a GC equipped with a HP-PLOT/Q column (30 $\mathrm{m} \times 0.32 \mathrm{~mm} \times 20 \mu \mathrm{m}$, Agilent Technologies, Wilmington, DE, USA).

The GC front detector FID was heated to $250{ }^{\circ} \mathrm{C}$, and the fuel gas (hydrogen) flow was set to $30 \mathrm{~mL} / \mathrm{min}$ to maintain the flame. The air flow was set to optimum at $400 \mathrm{~mL} / \mathrm{min}$ and the makeup flow was set at $25 \mathrm{~mL} / \mathrm{min}$. The column was used at an initial temperature of $60{ }^{\circ} \mathrm{C}$ maintained for $2 \mathrm{~min}$. After the temperature reached equilibrium for $0.5 \mathrm{~min}$, the oven was heated at a rate of $5{ }^{\circ} \mathrm{C} / \mathrm{min}$ until it reached $150{ }^{\circ} \mathrm{C}$; the temperature was then maintained for $1 \mathrm{~min}$. The oven max temperature could not exceed $250^{\circ} \mathrm{C}$ and the total GC run time was approximately $5 \mathrm{~min}$. All GC measurement results were prepared using the Agilent Integrated GC Software.

\subsection{Statistical Analysis}

Excel Ver. 2013 software was used for statistical analysis. Student's $t$-tests were used to identify significant differences between two treatment groups. A probability level of $5 \%(p \leq 0.05)$ indicates a significant difference.

\section{Conclusions}

As CSAOS2 was found to be a specifically upregulated JA synthesis gene in tea flowers exposed to T. hawaiiensis attack [16], we provided further evidence that CsAOS2 functions in JA synthesis using N. benthamiana transient expression analysis and subcellular localization analysis. Moreover, in this study, JA in tea flowers showed different functions from tea leaves and other flowers and did not significantly influence the metabolite profiles of tea flowers and the formation of ethylene; this suggests that JA might instead have other functions such as changing stereochemical configurations (Figure 7). The information presented here will help us determine the involvement of phytohormones in interactions between the flowers of horticultural crops such as tea plants and insects. 


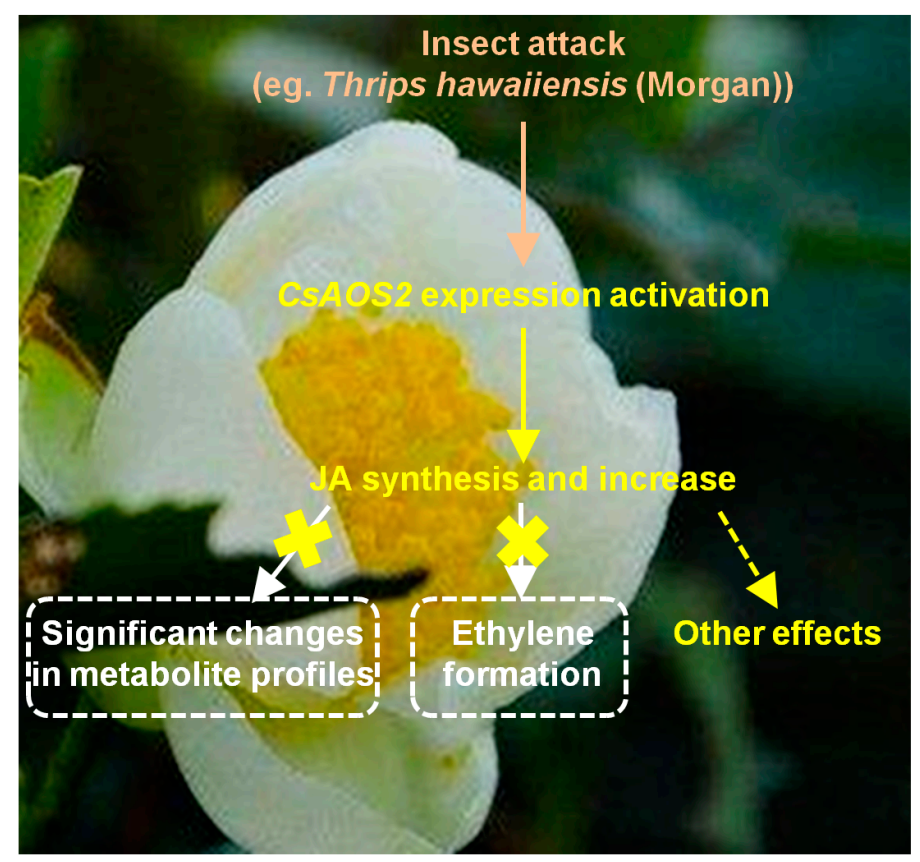

Figure 7. Summary on effect of insect (Thrips hawaiiensis (Morgan)) attack on pathway of JA and its influence on tea flowers.

Supplementary Materials: Supplementary materials can be found at http:/ /www.mdpi.com/1422-0067/19/8/2440/s1.

Author Contributions: Z.Y. conceived and designed the experiments; Q.P., Y.Z., Y.L., L.Z., X.X., Y.J., F.D., J.L. and J.T. conducted the experiments; Z.Y. and Q.P. analyzed the results and wrote the manuscript; all authors read and approved the final manuscript.

Acknowledgments: This study was supported by the National Natural Science Foundation for Young Scholars of China (31500244), the Youth Innovation Promotion Association of Chinese Academy of Sciences (Y821131001), the Pearl River Science and Technology New Star Fund of Guangzhou (201806010018), the Guangdong Province Higher Vocational Colleges \& Schools Pearl River Scholar, the Guangdong Special Support Plan for Training High-Level Talents (2016TQ03N617), and the Guangdong Innovation Team of Modern Agricultural Industry Technology System (2017LM1143).

Conflicts of Interest: The authors declare no conflicts of interest.

\section{Abbreviations}

$\begin{array}{ll}\text { AOS } & \text { Allene oxide synthase } \\ \text { JA } & \text { Jasmonic acid } \\ \text { LA } & \text { Linoleic acid } \\ \text { LOX } & \text { Lipoxygenases } \\ \text { AOC } & \text { Allene oxide cyclase } \\ \text { AdoMet } & \text { S-adenosyl-L-methionine } \\ \text { SAM } & \text { S-adenosyl-L-methionine synthetase } \\ \text { ACC } & \text { 1-Aminocyclopropane-1-carboxylic acid } \\ \text { ACS } & \text { ACC synthase } \\ \text { ACO } & \text { ACC oxidase } \\ \text { EIN } & \text { Ethylene-insensitive } \\ \text { 13-HPOT } & \text { 13(S)-hydroxy linolenic acid } \\ \text { GC-MS } & \text { Gas chromatography-mass spectrometry } \\ \text { UPLC-QTOF-MS } & \text { Ultra-performance liquid chromatography/quadrupole time-of-flight mass spectrometry }\end{array}$




\section{References}

1. Pichersky, E.; Gershenzon, J. The formation and function of plant volatiles: Perfumes for pollinator attraction and defense. Curr. Opin. Plant Biol. 2002, 5, 237-243. [CrossRef]

2. Dong, F.; Fu, X.M.; Watanabe, N.; Su, X.G.; Yang, Z.Y. Recent advances in the emission and functions of plant vegetative volatiles. Molecules 2016, 21, 124. [CrossRef] [PubMed]

3. Maffei, M.E.; MithÖfer, A.; Boland, W. Before gene expression: Early events in plant-insect interaction. Trends Plant Sci. 2007, 12, 310-316. [CrossRef] [PubMed]

4. Negre, F.; Kish, C.M.; Boatright, J.; Underwood, B.; Shibuya, K.; Wagner, C.; Clark, D.G.; Dudareva, N. Regulation of methylbenzoate emission after pollination in snapdragon and petunia flowers. Plant Cell 2003, 15, 2992-3006. [CrossRef] [PubMed]

5. Wu, J.Q.; Hettenhausen, C.; Meldau, S.; Baldwin, I.T. Herbivory rapidly activates MAPK signaling in attacked and unattacked leaf regions but not between leaves of Nicotiana attenuata. Plant Cell 2007, 19, 1096-1122. [CrossRef] [PubMed]

6. Neiland, M.R.M.; Wilcock, C.C. Fruit set, nectar reward, and rarity in the Orchidaceae. Am. J. Bot. 1998, 85, 1657-1671. [CrossRef] [PubMed]

7. Chen, Y.Y.; Zhou, Y.; Zeng, L.T.; Dong, F.; Tu, Y.Y.; Yang, Z.Y. Occurrence of functional molecules in the flowers of tea (Camellia sinensis) plants: Evidence for a second resource. Molecules 2018, 23, 790. [CrossRef] [PubMed]

8. Lin, Y.S.; Wu, S.S.; Lin, J.K. Determination of tea polyphenols and caffeine in tea flowers (Camellia sinensis) and their hydroxyl radical scavenging and nitric oxide suppressing effects. J. Agric. Food Chem. 2003, 51, 975-980. [CrossRef] [PubMed]

9. Yang, Z.Y.; Tu, Y.Y.; Baldermann, S.; Dong, F.; Xu, Y.; Watanabe, N. Isolation and identification of compounds from the ethanolic extract of flowers of the tea (Camellia sinensis) plant and their contribution to the antioxidant capacity. LWT Food Sci. Technol. 2009, 42, 1439-1443. [CrossRef]

10. Wang, L.; Xu, R.; Hu, B.; Li, W.; Sun, Y.; Tu, Y.; Zeng, X. Analysis of free amino acids in Chinese teas and flower of tea plant by high performance liquid chromatography combined with solid-phase extraction. Food Chem. 2010, 123, 1259-1266. [CrossRef]

11. Dong, F.; Yang, Z.Y.; Baldermann, S.; Kajitani, Y.; Ota, S.; Kasuga, H.; Imazeki, Y.; Ohnishi, T.; Watanabe, N. Characterization of L-phenylalanine metabolism to acetophenone and 1-phenylethanol in the flowers of Camellia sinensis using stable isotope labeling. J. Plant Physiol. 2012, 169, 217-225. [CrossRef] [PubMed]

12. Yang, Z.Y.; Dong, F.; Baldermann, S.; Murata, A.; Tu, Y.Y.; Asai, T.; Watanabe, N. Isolation and identification of spermidine derivatives in flowers of tea (Camellia sinensis) plants and their distributions in floral organs. J. Sci. Food Agric. 2012, 92, 2128-2132. [CrossRef] [PubMed]

13. Zhou, Y.; Dong, F.; Kunimasa, A.; Zhang, Y.; Cheng, S.; Lu, J.; Zhang, L.; Murata, A.; Mayer, F.; Fleischmann, P.; et al. Occurrence of glycosidically conjugated 1-phenylethanol and its hydrolase $\beta$-primeverosidase in tea (Camellia sinensis) flowers. J. Agric. Food Chem. 2014, 62, 8042-8050. [CrossRef] [PubMed]

14. Dong, F.; Zhou, Y.; Zeng, L.T.; Peng, Q.Y.; Zhang, L.; Su, X.G.; Watanabe, N.; Yang, Z.Y. Elucidation of differential accumulation of 1-phenylethanol in flowers and leaves of tea (Camellia sinensis) plants. Molecules 2016, 21, E1106. [CrossRef] [PubMed]

15. Matsuda, H.; Nakamura, S.; Morikawa, T.; Muraoka, O.; Yoshikawa, M. New biofunctional effects of the flower buds of Camellia sinensis and its bioactive acylated oleanane-type triterpene oligoglycosides. J. Nat. Med. 2016, 70, 689-701. [CrossRef] [PubMed]

16. Zhou, Y.; Zeng, L.T.; Liao, Y.Y.; Dong, F.; Peng, Q.Y.; Li, J.L.; Tang, J.C.; Watanabe, N.; Yang, Z.Y. Insect (Thrips hawaiiensis (Morgan)) change the stereochemical configuration of 1-phenylethanol emitted from tea (Camellia sinensis) flowers. RSC Adv. 2017, 7, 32336-32343. [CrossRef]

17. Zhou, Y.; Peng, Q.Y.; Zeng, L.T.; Tang, J.C.; Li, J.L.; Dong, F.; Yang, Z.Y. Study of the biochemical formation pathway of aroma compound 1-phenylethanol in tea (Camellia sinensis) flowers and other plants. Food Chem. 2018, 258, 352-358. [CrossRef] [PubMed]

18. Dong, F.; Yang, Z.Y.; Baldermann, S.; Sato, Y.; Asai, T.; Watanabe, N. Herbivore-induced volatiles from tea (Camellia sinensis) plants and their involvement in intraplant communication and changes in endogenous nonvolatile metabolites. J. Agric. Food Chem. 2011, 59, 13131-13135. [CrossRef] [PubMed] 
19. Han, B.Y.; Chen, Z.M. Composition of the volatiles from intact and mechanically pierced tea aphid-tea shoot complexes and their attraction to natural enemies of the tea aphid. J. Agric. Food Chem. 2002, 50, 2571-2575. [CrossRef] [PubMed]

20. Ishiwari, H.; Suzuki, T.; Maeda, T. Essential compounds in herbivore-induced plant volatiles that attract the predatory mite Neoseiulus womersleyi. J. Chem. Ecol. 2007, 33, 1670-1681. [CrossRef] [PubMed]

21. Zeng, L.T.; Liao, Y.Y.; Li, J.L.; Zhou, Y.; Tang, J.C.; Dong, F.; Yang, Z.Y. $\alpha$-Farnesene and ocimene induce metabolite changes by volatile signaling in neighboring tea (Camellia sinensis) plants. Plant Sci. 2017, 264, 29-36. [CrossRef] [PubMed]

22. Kongrit, D.; Jisaka, M.; Iwanaga, C.; Yokomichi, H.; Katsube, T.; Nishimura, K.; Nagaya, T.; Yokota, K. Molecular cloning and functional expression of soybean allene oxide synthases. Biosci. Biotechnol. Biochem. 2007, 71, 491-498. [CrossRef] [PubMed]

23. Itoh, A.; Schilmiller, A.L.; McCaig, B.C.; Howe, G.A. Identification of a jasmonate-regulated allene oxide synthase that metabolizes 9-hydroperoxides of linoleic and linolenic acids. J. Biol. Chem. 2002, 277, 46051-46058. [CrossRef] [PubMed]

24. Sivasankar, S.; Sheldrick, B.; Rothstein, S.J. Expression of allene oxide synthase determines defense gene activation in tomato. Plant Physiol. 2000, 122, 1335-1342. [CrossRef] [PubMed]

25. Farmaki, T.; Sanmartín, M.; Jiménez, P.; Paneque, M.; Sanz, C.; Vancanneyt, G.; León, J.; Sánchez-Serrano, J.J. Differential distribution of the lipoxygenase pathway enzymes within potato chloroplasts. J. Exp. Bot. 2007, 58, 555-568. [CrossRef] [PubMed]

26. Wasternack, C.; Hause, B. Jasmonates: Biosynthesis, perception, signal transduction and action in plant stress response, growth and development. An update to the 2007 review in Annals of Botany. Ann. Bot. 2013, 111, 1021-1058. [CrossRef] [PubMed]

27. Song, W.C.; Brash, A.R. Purification of an allene oxide synthase and identification of the enzyme as a cytochrome P-450. Science 1991, 253, 781-784. [CrossRef] [PubMed]

28. Song, W.C.; Funk, C.D.; Brash, A.R. Molecular cloning of an allene oxide synthase: A cytochrome P-450 specialized for metabolism of fatty acid hydroperoxides. Proc. Natl. Acad. Sci. USA 1993, 90, 8519-8523. [CrossRef] [PubMed]

29. Turner, J.G.; Ellis, C.; Devoto, A. The jasmonate signal pathway. Plant Cell 2002, 14, S1531-S1564. [CrossRef]

30. Farmer, E.E.; Ryan, C.A. Octadecanoid precursors of jasmonic acid activate the synthesis of wound-inducible proteinase inhibitors. Plant Cell 1992, 4, 129-134. [CrossRef] [PubMed]

31. Howe, G.A. Jasmonates as signals in the wound response. J. Plant Growth Regul. 2004, 23, 223-237. [CrossRef]

32. Keinänen, M.; Oldham, N.J.; Baldwin, I.T. Rapid HPLC screening of Jasmonate-induced increases in tobacco alkaloids, phenolics, and diterpene glycosides in Nicotiana attenuata. J. Agric. Food Chem. 2001, 49, 3553-3558. [CrossRef] [PubMed]

33. Porat, R.; Borochov, A.; Halevy, A.H. Enhancement of petunia and dendrobium flower senescence by jasmonic acid methyl ester is via the promotion of ethylene production. Plant Growth Regul. 1993, 13, $297-301$. [CrossRef]

34. Wang, K.L.C.; Li, H.; Ecker, J.R. Ethylene biosynthesis and signaling networks. Plant Cell 2002, 14, S1311-S1351. [CrossRef]

35. Dar, T.A.; Uddin, M.; Khan, M.M.A.; Hakeem, K.R.; Jaleel, H. Jasmonates counter plant stress: A Review. Environ. Exp. Bot. 2015, 115, 49-57. [CrossRef]

36. Allmann, S.; Halitschke, R.; Schuurink, R.C.; Baldwin, I.T. Oxylipin channelling in Nicotiana attenuata: Lipoxygenase 2 supplies substrates for green leaf volatile production. Plant Cell Environ. 2010, 33, 2028-2040. [CrossRef] [PubMed]

37. Halitschke, R.; Baldwin, I.T. Antisense LOX expression increases herbivore performance by decreasing defense responses and inhibiting growth-related transcriptional reorganization in Nicotiana attenuata. Plant J. 2003, 36, 794-807. [CrossRef] [PubMed]

38. Vick, B.A.; Zimmerman, D.C. Pathways of fatty acid hydroperoxide metabolism in Spinach leaf chloroplasts. Plant Physiol. 1987, 85, 1073-1078. [CrossRef] [PubMed] 
39. Rostás, M.; Ton, J.; Mauch-Mani, B.; Turlings, T.C. Fungal infection reduces herbivore-induced plant volatiles of maize but does not affect naive parasitoids. J. Chem. Ecol. 2006, 32, 1897. [CrossRef] [PubMed]

40. Li, R.; Wang, M.; Wang, Y.; Schuman, M.C.; Weinhold, A.; Schäfer, M.; Baldwin, I.T. Flower-specific jasmonate signaling regulates constitutive floral defenses in wild tobacco. Proc. Natl. Acad. Sci. USA 2017, 114, E7205-E7214. [CrossRef] [PubMed] 